\title{
Boom or Bust? Embedding Entrepreneurship in Education in Australia
}

\begin{abstract}
Purpose - The purpose of this paper is to evaluate the status of entrepreneurship education (EE) in Australia, replicating and expanding a similar study in 2015. Our aim is to review neoteric global best practice EE initiatives, enabling the examination and embedding of EE offerings and initiatives at 40 Higher Education Institutions (HEIs) in Australia.

Design/methodology/approach - We introduce a review of prominent and recent global EE scholarship; enabling an iterative and emergent inquiry perspective aligned to inductive and nascent multi-method empirical research associated with theoretical underpinnings of symbolic and substantive management theory.

Findings - This paper highlights the sparse and inconsistent distribution of EE programs and initiatives across all 40 Australian HEIs, particularly against the backdrop of rapidly expanding start-up and entrepreneurship ecosystems. Furthermore, outcomes provide best practice EE initiatives, which included staff mobility and transferability of skills. HEIs in Australia are experiencing a moderate EE boom, albeit marginally down on global EE transformation initiatives. Research limitations/implications - limitation of the data is subject to availability and accuracy of online documents and material resources, although implications have been mitigated using multi-method research design.
\end{abstract}

Practical implications - The findings provide critical grounding for researchers, practitioners and HEIs wishing to enhance EE within ever-expanding entrepreneurship ecosystems.

Originality/value - This study is the first multi-methods enquiry into the status of EE in Australia, consisting of quantitative, qualitative and algorithmic methods.

Keywords - Entrepreneurship education, substantive and symbolic, entrepreneurship education programs.

Paper type - Research paper.

Acknowledgements - Dr Susan Rushworth for the many hours of data collection and research assistance, and Claudia Shwetzer, the originator of the founding research in 2014.

\section{Introduction}

Since the first global entrepreneurship program at Harvard Business School was delivered in 1947, and after the first prominent Australian course at Swinburne University of Technology in 1989, entrepreneurship education (EE) programs have grown rapidly (Maritz, 2017; Nabi et al., 2017). It must be noted that EE is not only intended for people who want to become self-employed or employers, but also immensely valuable for anyone working directly for an entrepreneur and for anyone in larger corporations who has entrepreneurs as clients, suppliers or partners. The alignment between the entrepreneurial mindset and various 'future of work' capabilities is also not missed in various industry reports (e.g., WEF, 2018) and is as relevant for new graduates as it is for mid- or late-career professionals.

The last decade, in particular, has not only seen high growth in such programs, but also significant growth in entrepreneurship ecosystems and support structures that enhance entrepreneurship (Kuratko \& Morris, 2018; Belitski \& Heron, 2017; Miles et al., 2017). Not only are higher education institutions (HEIs) jumping into Australia's startup boom (Scandlon \& MCCormack, 2018; Alexander, 2018), but so too are the federal, state and local governments, accelerators/incubator programs, chambers of commerce, connections and virtual hubs, corporations, co-working spaces, events/pitch/ awards programs, hackathons, technology communities, industry associations/peak bodies, innovation hubs, media/tools/advocacy, Schools and STEAM programs, training/ support, policy makers and all encompassing entrepreneurship ecosystems (Liguari et al., 2019; Bliemel et al., 2019; Spigel, 2015; Renando, 2018). For instance, the number of Australian accelerator has been growing nearly $40 \%$ per year for the last 10 years (Bliemel, 2019). 
Mason (2019), in a Keynote address at the ACERE (2019), provided emphasis of the role of entrepreneurship education toward enhancing entrepreneurship ecosystems.

Embedding the integration of EE and entrepreneurship ecosystems in Australia suggests three main patterns. First, contra to a recent report by the Universities Australia peak body suggesting equal EE engagement by all HEIs, the present review highlights the sparse and inconsistent distribution of EE initiatives at Australian HEIs (Maritz et al., 2015; O'Connor, 2013), particularly against the backdrop of rapidly expanding start-up and entrepreneurship ecosystems (UIIN, 2018; Renando, 2018). Promoting and implementing EE programs entails substantial investment of time and resource, so it is critically important to take stock of what we currently know about the range of EE initiatives in Australian HEIs. Second, neoteric reviews highlight benchmark and prominent EE initiatives that may be impactful and measurable across global boundaries, inclusive of cocurricular activities, not just coursework (Kuratko \& Morris, 2018; Morris et al., 2013; Neck \& Corbett, 2018; Maritz, 2017; Nabi et al., 2017; OECD, 2018; QAA, 2018). As well as examining a range of EE impact and outcome measures, it is necessary to examine the different methodological issues and pedagogical methods that underpin them. Third, few reviews focus on the nexus of EE and HEI strategic intent, notably the emergence of the entrepreneurial university (Nguyen and Maritz, 2019). As such, there is a need to examine the interface between HEI strategic intentions and delivery of EE, thereby identifying the substantive and symbolic nature of EE in Australian HEIs.

These three distinctly yet related research gaps form the rationale for this article. Our aim is to review recent global best practice EE initiatives, enabling the examination and embedding of EEPs and entrepreneurship offerings at 40 HEIs in Australia. We believe our main contributions to the EE body of knowledge is the first multi-methods study of EE program offerings in Australian HEIs, coupled with an innovative algorithmic method to examine the interface between HEI strategic entrepreneurship intentions and EE program offerings. New insights from this article provide a neoteric approach to the body of knowledge by providing a framework to embed EE initiatives within entrepreneurship ecosystems. The article argues that whilst EE in Australian HEIs has grown rapidly, much is still to be done to enhance EE substantive and symbolic actions to further develop entrepreneurship ecosystems in Australia. The findings provide critical grounding for researchers, practitioners and HEIs wishing to enhance EE within ever-expanding entrepreneurship ecosystems.

We commence our study with a review of prominent and neoteric global EE literature, followed by a replication and extension study of the Maritz et al (2015) research in the form of a quantitative examination of EE offerings by Australian HEIs. We then conduct qualitative inquiry to include interviews and narratives from leading EE scholars in Australia, followed by an algorithm that generates thematic clustering based on keyword co-occurrence to examine the interface between HEI strategic entrepreneurship intent and EE offerings. In the discussion we provide outcomes of the research against the background of our three main patterns as identified above. The article concludes with implications of new EE perspectives in HEIs and suggestions for directions of future research.

\section{Literature}

To enable and guide our design and methodological approach to evaluate the status of EE in Australia, we introduce a review of prominent, recent and emerging scholarship on global EE. We commence with best practice scholarship within a global context, more specifically, The United Kingdom, United States of America and Organisation for Economic Co-Operation (OECD). These regions were included due to emergence, impact, quality, innovation and recency of prominent EE initiatives. This is followed by nascent scholarship on entrepreneurship education programs (EEPs), scholarship of EE, and future trajectory of EE and entrepreneurship education ecosystems. 


\section{Global Entrepreneurship Education Imperatives}

In this section, we integrate 3 recent and prominent EE initiatives; consisting of the United Kingdom's Quality Assurance Agency Guidance on Enterprise and Entrepreneurship Education (QAA, 2018), OECD Skills Studies on Supporting Entrepreneurship and Innovation in Higher Education in The Netherlands (OECD/EU, 2018) and Entrepreneurship Programs and the Modern University (Morris et al., 2013).

The QAA (2018) guidance reflects current thinking and practice in Enterprise and Entrepreneurship Education and is intended to inform, enhance and promote the development of Enterprise and Entrepreneurship Education across UK higher education. Rather unique within the UK context, the terms entrepreneurship and enterprise are seen as different, yet integrating concepts. They define enterprise as, "the generation and application of ideas, which are set within practical situations during a project or undertaking" (QAA, 2018:p7). Within this context, they define entrepreneurship as, "the application of enterprise behaviours, attributes and competencies into the creation of cultural, social or economic value. This can, but does not exclusively, lead to venture creation" (QAA, 2018:p7). When enterprise and entrepreneurship are used together they are termed 'entrepreneurial'. Mindful of contextual terminology, we continue this study using the terminology of entrepreneurship, referring to EE as knowledge transfer, regarding how, by whom, and with what effects, opportunities to create future goods and services are discovered, evaluated and exploited.

Aims of EE from a student's perspective include inclusivity, wide participation, positive influence on creativity, flexibility and the innovation process, positive impact on learning outcomes and self-efficacy, improving stakeholder engagement, demystifying career opportunities and enhancing employability and significantly increasing start-up rates. Delivering EE needs to be mindful of the role, attributes and tasks of EE educators. Roles include EE educators as catalysts to plan and deliver effective entrepreneurship curricula, build collaborative relationships, motivate and inspire students. Other roles include the mentors, guest speakers, judges and other people curated and coordinated by the educators to enhance student learning. Attributes include inclusive leadership, innovative, enterprising, reflective, engaging, enabling and relevant. And tasks include providing pathways towards a designated outcome, designing constructively aligned curricula, enhancing student experience beyond specific teaching activity or assessment, contributing to the achievement of institutional strategy, influencing institutions and the broader educator community/ecosystem and providing multi-disciplinary insights such as finance, intellectual property protection, incubators and networks. Delivery methods include a contextualized approach that enables students to enhance their entrepreneurial capabilities, usually experiential in nature; most often cross-disciplinary and a close integration of theory and practical component. Final delivery components consist of assessment, evaluation and impact; which are addressed in the literature below.

This QAA (2018) view the student learning experience as the nucleus of EE, consisting of the learning journey, towards entrepreneurial effectiveness, developing an entrepreneurial mindset, developing entrepreneurial capability, entrepreneurial effectiveness and entrepreneurial graduate outcomes. The consortium also places emphasis on the supportive institution, comprising factors to consider regarding location within an institution (usually business schools in a UK context), supporting the educators, institutional strategy and vision, funding and evaluating the impact and success of EE. The QAA (2018) approach is closely aligned to the research of Nabi et al. (2017), who developed an integrated teaching model framework encompassing EE impact and underpinning pedagogy. Their study found that EE impact research predominantly focuses on short-term and subjective outcome measures and tends to severely underdescribe the actual pedagogies being tested. The QAA (2018) guidance provides pathways for EE educators to overcome such shortsightedness. 
In a similar vain to the QAA (2018) guidance, the OECD/EU (2018) study provides a robust framework to supporting EE in higher education in the Netherlands. In particular, this publication presents the findings and recommendations of the HEInnovate review of the impact of higher education institutions (HEIs) on entrepreneurship and innovation in the Netherlands. HEInnovate is a Dutch initiative aimed at transforming HEIs into entrepreneurial organisations at European and global levels. As such, this approach is more directed at an institutional or strategic approach, whereas the QAA (2018) guidance is more practitioner and operational in nature. The OECD/EU (2018) study encapsulates the creation of value from scientific knowledge through economic and/or social use, referred to as 'valorisation'. This valorisation, or value add, supports collaboration between HEIs, joint entrepreneurial ecosystem initiatives, boosts research activities, enhances interdisciplinary and support entrepreneurial start-up activity (Miles et al., 2017). In essence, applying HEInnovate to higher education, enhancing the organizational capacity of higher education, building entrepreneurial capacity through teaching and learning, enhancing knowledge exchange and strengthening entrepreneurship support in higher education, enhances valorisation.

In building capacity through teaching and learning, the study (OECD/EU, 2018) proposes developing an entrepreneurial mindset, problem based learning (similar to experiential learning initiatives), enhancing interdisciplinary, capacity building for innovation in teaching and learning, digital learning environment, promoting lifelong learning, associate degrees and awards, exchange platforms that enrich education, empowering students to co-design activities, linking students with the local/regional and global economy, entrepreneurship education, social entrepreneurship, future policies for EE, measuring the impact of $\mathrm{EE}$, and evaluating impacts on entrepreneurial skills and outcomes, mindsets and intentions. The OECD/EU (2018) study provides inferences to strengthen entrepreneurship support in HEIs, inclusive of the business start-up environment, students as game changers, supporting students in start-up failures, alumni support, targeted and internally connected start-up support and building effective regional entrepreneurship ecosystems.

From an operational perspective, and more aligned to the QAA (2018) guidance, the OECD/EU (2018) study provides a competency framework to guide EE. Such initiatives include differentiation of entrepreneurial learning goals (non-cognitive and cognitive), alignment and progression between programs, identifying learning outcome aligned to career outcomes, meaningful benchmarking indicators and national impact measures. National impact measures (Naby et al., 2017) align closely to our study of EE in Australia, where no such measures have been realized within the Australian context.

Our final global representation identifies entrepreneurship programs and the modern university from a USA perspective (Morris et al., 2013). The purpose of their volume is to "take stock of how entrepreneurship is being implemented on university campuses, and to provide a roadmap for program developers to follow" (ibid. p. ix) and identifies entrepreneurship educators as disruptors, promoters of dreams, agents of change, facilitators of opportunities and generators of empowerment. The authors provide a holistic approach to enhancing EE, by exploring facets of the evolution of entrepreneurship in HEIs, organization structures for entrepreneurship programs, program outcomes (competency based approach), establishing the core curriculum, experiential learning in entrepreneurship, and the way forward (or as they refer to it, the ongoing revolution). The evolution includes domain areas within entrepreneurship, purpose and philosophy of entrepreneurship and the role of educators in delivering EE programs. Organizational structures include department of entrepreneurship (including exemplars from USA perspectives), supporting structures, and the maturation and legitimization of entrepreneurship as a discipline. A competency-based approach toward assessing program outlines provides guidelines for metrics, impact and purpose and objectives of EE programs. Establishing the core curriculum includes traditional models, establishing foundations, moving beyond the business school (such as STEAM, multi- 
disciplinary) and EE as an innovation stream. Experiential learning refers to learning by doing or from doing things of others. As an integral component of EE, this includes the nature of an entrepreneurial experience, learning styles of students, experiential opportunities, and linking experiential learning to the curriculum and beyond. Beyond includes course-based experiences, campus-based experiences, community-based experiences and international experiences. The ongoing revolution discusses a number of potential trends and developments, such as, integration of program foci to become more comprehensive, creative abrasion between the applied center and academic program, higher-impact engagement, more cross-disciplinary collaboration, ownership of niches, emergent structural forms, net resource generator, new staffing models and entrepreneurship as a culture driver on campus. They also list a few challenges, such as the danger of complacency, respect for research, a threat of dilution, risk in the classroom (such as financials, career, family, social or psychic), shortage of qualified faculty, cyber culture challenge, the administrative leadership revolving door problem, academic entrepreneurship leadership (such as Chair or discipline leadership) and the challenge of assessment .

Kuratko (2014) mentions the entrepreneurial imperative of the $21^{\text {st }}$ century that each entrepreneurship educator's goal should be able to make a difference in the theory, the process or practice of entrepreneurship. If this is done, the discipline of entrepreneurship can be the model for interdisciplinary research and study, at the forefront of scholarship in action, a leader in pedagogical innovation, the standard setter for experiential learning, the model for community engagement, the archetype for new approaches to fundraising and resource generation and at the forefront of changes to staffing and reward systems. Many of these initiatives relate to the development of the entrepreneurial university (Nguyen \& Maritz, 2019), embedding EE into education and enhancing human capital through the development of initiatives such as accelerators within entrepreneurship ecosystems (Bliemel et al., 2019; Liguari et al., 2019; Miles et al., 2017).

\section{Entrepreneurship Education Programs}

Entrepreneurship education programs (EEPs) form an integral component of the wider entrepreneurship education ecosystem (Belitski \& Heron, 2017) and our study summarizes the components and contextualization of EEPs from the work of Maritz (2017). Originally based on EEP models by Alberti et al (2004), Fayolle and Gailly (2008) and Maritz and Brown (2013); the Maritz (2017) EEP model now incorporates transformational agendas such as entrepreneurship ecosystems, innovative entrepreneurship content (such as blockchain and big data), entrepreneurship tools (such as lean startup, business model design, algorithmic transformation) and contextual inferences. The Maritz (2017) EEP model consists of contextualization of entrepreneurship education ecosystems as a central them to the model, with satellite components consisting of entrepreneurship ecosystems, outcomes, objectives, assessment, content, pedagogy and audience. Due to ever-changing diversity of stakeholders, cross-disciplinary EE, type of entrepreneurship and many other transformative EE initiatives, the EEP components are integrative and dynamic in nature. This dynamic nature is further evidenced by the knowledge transfer when EE educators move between HEIs, providing new EE initiatives based upon previous experience (Maritz, 2017). Notwithstanding the dynamic nature, it is our own opinion that many cross-disciplinary EEPs are not strategically developed with appropriate entrepreneurship scholarly expertise, and that the EEP model may be used to overcome such shortcomings. Entrepreneurship leadership of programs (and discipline leadership) also facilitates a guidance approach to developing professional EEPs, together with the appropriate educators delivering EEPs (see, for example, Maritz et al., 2015).

Closely aligned to the EEP approach, Neck and Corbett (2018) provide significant inference on the scholarship of teaching and learning entrepreneurship. They provide a summarized definition of EE, based upon a significant Delphi analysis from a large sample of senior entrepreneurship educators. Interestingly, many respondents stated that EE and 
enterprise education require significant integration (aligned with the QAA, 2018 study). They define EE as "developing the mindset, skill set and practice necessary for starting new ventures" (Neck and Corbett, 2018: p30). Their study also elaborates on the role of entrepreneurship educators, once again highlighting inconsistencies of EE delivery (Maritz et al., 2015). They also postulate a transition to teaching approaches based on adult learning, namely andragogy and heutagogy, based upon previous studies in this regard (see, for example, Jones et al., 2012). The Neck and Corbett (2018) study provides an interesting continuum of EEPs, consisting of ideal scenarios on various EE approaches. These include instructional approaches (pedagogy to andragogy to heutagogy), educator role (lecturer to coach to facilitator), student role (passive to simulating to doing/experiential), center of learning (educator to shared to student) and EE outcomes (awareness to mindset to startup). The ideal scenarios are somewhat optimistic, taking that many entrepreneurship subjects worldwide are delivered by cross-disciplinary academics in various settings and contexts (Bliemel, 2018; Maritz et al., 2015).

Our final section of literature provides a more holistic view of examining the future trajectory of entrepreneurship (Kuratko and Morris, 2018). Their view is informed by transformation of entrepreneurship as a discipline, in that entrepreneurship is being defined in different ways... by different audiences! They examine six major trajectories that will significantly influence the future of the discipline. These trajectories include: (1) Why teach entrepreneurship - a clear purpose, (2) What is taught in entrepreneurship the content, (3) How entrepreneurship is taught - the delivery mechanism, (4) Organizing entrepreneurship - the structure, (5) outcomes of teaching entrepreneurship - the metrics, and leadership of entrepreneurship programs academic entrepreneurs. These trajectories are well aligned to the EEP components postulated by Maritz (2017), and of particular significance, the final trajectory on academic leadership and ecosystems (such as Chairs in entrepreneurship and Professors of Practice). Kuratko and Morris believe this to be an individual with academic stature, clear vision regarding how entrepreneurship can inform other disciplines, and a strong sense of how other disciplines inform entrepreneurial activity. One question their research, together with the EEP research of Maritz (2017) may highlight, is assessing how entrepreneurial are our entrepreneurship programs? This is however currently outside the ambit of the current research project. We further believe an additional trajectory to be included should embrace the entrepreneurship ecosystem, and more particularly, the development of the entrepreneurial university; thus allowing HEIs to become more entrepreneurial in their transformation and endeavours (see, for example, Nguyen and Maritz, 2019). Next we provide an overview of our multi-method 3-stage design and methodology approach.

\section{Methods}

We introduced a review of prominent and neoteric global EE scholarship and literature; enabling an emergent inquiry perspective aligned to inductive and nascent research. Our nascent design and methodological approach is based on foundations of symbolic and substantive management theory. Symbolic management view managerial action could be measured on two levels, substantive and symbolic (Pfeffer, 1981). For the former, actions produce tangible and objectively measureable results such as profit, capital expenditure, budget and resource allocation. On the symbolic level, the actions produce intangible and subjective results like shared meanings, beliefs, commitment and loyalty. From EE perspectives, substantive actions may produce tangible and objectively measured results like graduate capabilities, learning outcomes, pedagogy, impact and content. From a symbolic perspective, intangible and subjective results may influence shared meanings, perceived impact, beliefs, stakeholder commitment and adoption of entrepreneurship ecosystems.

This study is the first multi-methods enquiry into the status of EE in Australia. Our approach to methodological fit, referring to internal consistency among elements of this article is based on a nascent archetype regarding iterative open-ended inquiry, few formal measures, thematic content analysis and preliminary testing of hybrid quantitative and 
qualitative data (Edmonson \& MCManus, 2007). Our 3-stage design approach aligns with the 3 research gaps identified in this research, based upon existing bet practice EE, examination of current EE offerings and initiatives, and measuring the integration of HEI strategic intent on entrepreneurship.

Quantitative methods (stage 1) include an examination of EEPs and entrepreneurship offerings at 40 HEIs in Australia, whereas qualitative methods (stage 2) include interviews (16) and narratives (6) from leading EE scholars in Australia. This study is in essence a replication and extension study. It is a replication of the Maritz et al (2015) study of the status of entrepreneurship education in Australia, and an extension from a point of view of recency of developments and initiatives in EE (QAA, 2018; Nabi et al., 2017; Neck \& Corbett, 2018; Kuratko \& Morris, 2018; OECD/EU, 2018; Morris et al., 2013; Maritz, 2017), coupled with examination of the latest EEP and entrepreneurship offerings at Australian HEI. From an entrepreneurship discipline contextualization perspective, we apply the findings of a study by Maritz and Donovan (2015) whereby they provide specific contextualization between entrepreneurship and innovation education. Despite significant integration between these two disciplines, this study is particularly focused on EE. We also provide a unique approach by integrating symbolic and substantive theoretical underpinnings, primarily as a result of our qualitative analyses.

Our quantitative component somewhat resembles the design and methods of the Maritz et al (2015) study, with the exception of updates on measurement items, coupled with associated points allocations. Measurement updates include items such as entrepreneurship academic leadership, online offerings, cross-disciplinary offerings, practice integration (such as professors of practice and/or entrepreneurs in residence), associated incubators/accelerators and entrepreneurship ecosystems. These additions were derived to develop categories and codes from the recent developments in global EE (applying the literature refereed to in the previous paragraph). A methodological outcome is to rank the HEIs from top to bottom (using the points indicator), but the rank is not to identify one HEI as being superior/inferior to another/others, but rather to identify areas of expertise, transformation and development and relative opportunities for each HEI. Rankings can easily change or be manipulated such as new calculation points on a per-student basis or other derivative measures.

Similar to the 2015 study, data was collected based on content analysis using published data on HEI website pages enabling equivalence issues such as sample, instrument and data analysis equivalence. Categories and items are depicted in Table 1. Data was accessed between 1 November 2018 and 14 January 2019. Compound ranking were tabulated using a points-per-item, using the following allocation (all within entrepreneurship contexts): full EEPs ( 6 points), major specialization (4 points), minor specialization ( 2 points), subject about/core ( 2 points), subject related ( 1 point), online about/core only ( 2 points), online related ( 1 point), subject additional offered online (1 point), core cross-disciplinary ( 2 points), related cross-disciplinary (1 point), Chair in entrepreneurship ( 3 points), entrepreneur in residence ( 2 points), professor of practice ( 2 points), associated incubator/accelerator ( 2 points), associated ecosystem ( 2 points), and strategic entrepreneurship intent (3 points). As this research component is descriptive in nature (compares data from 2014-2019), the intention is not to measure the effect, impact and outcomes of these entrepreneurship initiatives, but to document the change in occurrence and offerings of such EEPs, subjects and initiatives.

The qualitative component (stage 2 and an extension to our previous 2015 study), however, provides opportunity for inferences and further clarification. As such, in this research, the qualitative data allows nascent emergent inquiry perspectives, allowing substantive or symbolic perspectives. We adopted emergent inquiry as an extension of participative action research (Keegan, 2009; Walker \& Foote, 2000) as a method to guide our approach. The data from sixteen EE educators were coded in an attempt to describe and develop a theoretical understanding of the responses, being a combination of 
facilitation, observation, leadership, analysis, critical thinking, reflectivity, emotional and sensory awareness, improvisation, creating narrative and creative thinking (Keegan, 2009). In addition, 6 EE educators, representing a sample from the top ten HEIs in Table 1 , were randomly nominated to create (defined) narrative pieces on EE within their respective HEIs. These pieces identified best practice EE initiatives within Australia.

We then introduce additional rigour to the analysis, by providing an algorithmic content analysis study of the strategic entrepreneurship intent of HEI in Australia (stage 3). This provides a distinction of those HEIs, which have significant entrepreneurship intentions as represented in University strategic documents. Those HEIs with significant entrepreneurship intent rated 3 points; those with moderate entrepreneurship strategic intent rated 2 points; those with marginal entrepreneurship strategic intent rated 1 point; and finally, those with an absence of entrepreneurship strategic intent rated 0. A comprehensive explanation of this method and application is represented in Nguyen and Maritz (2019). In the next section, we provide an overview of the results from our research design.

\section{Findings and Discussion}

We integrate the three main patterns identifying the article research gaps to provide an iterative and nascent approach to EE offerings in an Australian HEI context. The three main patterns include what we currently know about EE programs in Australia and neoteric updates from this article (stage $1 / 2$ quantitative and qualitative components); prominent EE global initiatives; and the interface between EE and HEI entrepreneurship strategic intent (stage 3 Leximancer algorithm component).

\section{Stage 1 Entrepreneurship Education Offerings (Quantitative)}

We systematically coded and quantified data collected from HEI websites on 17 December 2018. The data consisted of focused measures where extent or amount is meaningful, essentially exploring EE quantity offerings (as opposed to detailed impact and quality, which opens opportunity for further research). The measures are summarized in Table 1, consisting of EEPs and EE support mechanisms (such as incubators, ecosystems and departmental leadership). Stage 1 is a replication study of the Maritz et al (2015) study, with extension of nascent support mechanisms. As such, we commence with a five-year longitudinal comparison of EEPs in Australian HEIs (2014 and 2019).

The replication component of this article consists of a quantitative measurement of EEPs, consisting of full programs, programs with majors and/or minors, and subjects either about or related to entrepreneurship. Findings reflect a somewhat subdued outcome between 2014 and 2019, with EEPs virtually identical (50 versus 53) and subjects (584 versus 463). The latter indicates a decline of approximately $20 \%$ over the five-year period. This status quo and decline are in stark contrast to the rise in EEPs in the US and the meteoric rise of private sector entrepreneurial training programs, such as accelerators (Bliemel, 2019), incubators, co-working spaces coupled with events series, etc. (Spigel, 2015; Renando, 2018), many of which receive some form of government support, too. While the findings indicate a rapid growth of online offerings, less than half of HEIs offer this delivery mode. Meanwhile, countless private sector online courses (MOOCs) are emerging. While HEIs have long been the dominant source for learning and development, they are increasingly subjected to the red queen effect in the race to provide transversal capabilities like entrepreneurship. These capabilities are increasingly in demand by students, employers and entrepreneurs (WEF, 2018)

The extension component includes new measures, primarily enabled by neoteric global EE initiatives, as identified in the literature section of this article. Data depicts that only one-third of HEIs have a Chair/Professor in entrepreneurship (also referred to as academic leadership or discipline leader); similarly for entrepreneurs in residence. This is contrary to global EE, where Professors and entrepreneurs in residence enjoy 
prevalence rates in excess of 60 percent. Only two HEIs employ Professors of Practice (POPs), a relatively new and unique concept within an Australian concept. POPs are engagement driven, as opposed to academic Professors who are research, teaching and leadership centric. We identify a significant growth in HEI accelerators and incubators, with almost half of Australian HEIs offering some sort of support in this regard. Similarly, half of the HEIs provide entrepreneurship ecosystem initiatives, such as student start-up funding, collaboration and networks, mentorship, access to markets and so on.

We tabulated the data (see Table 1) to provide inferences between the HEIs, although the aim of the article is not to rank the HEIs, but rather provide a holistic view of EE offerings and initiatives. HEIs may of course use the ranking to evaluate their relative opportunity to improve their EE profile. To facilitate nascent inquiry and support of the literature, we provide inferences from the HEI data. Of the 40 HEIs in Australia, it is noteworthy that the top 10 HEIs represent close to $60 \%$ of EE offerings. Aligned to current literature, this article highlights the sparse and inconsistent distribution of EE initiatives at Australian HEIs, particularly against the backdrop of rapidly expanding start-up and entrepreneurship ecosystems.

\section{Table 1: Entrepreneurship Education Initiatives at Australian Higher Education Institutions}

Insert Table 1 about here; Table is at the end of this paper.

In complete contrast to the aggregate stasis of the HEI from 2015 to 2019, there remains a remarkable level of fluidity in the EE space (see Figure 1). It is interesting to see the growth in EE offerings over the past 5 years of a few prominent HEIs. Such examples include the University of Canberra (19 to 9 rank), Flinders University (18 to 5 rank), La Trobe University (LTU) (21 to 4 rank) and the University of Technology Sydney (UTS) (9 to 2 ranking). Canberra's rise appears to be a factor of online dominance plus recent introduction of a Chair in entrepreneurship. Flinders introduced a strategic partnership with Temple University (USA), introduced EE teaching intensive specialists and accelerated EE programs and support initiatives. La Trobe introduced the Entrepreneurship Essential, whereby each course in the university required entrepreneurship content. In addition, LTU introduced a Chair in entrepreneurship, Professor of Practice, rapid acceleration of EE programs, online offerings and support initiatives. UTS introduced an array of majors in entrepreneurship, together with significant subjects and support mechanisms, further enhancing their vision of technology and creativity. Conversely, Swinburne University of Technology (SUT) declined in ranking from 1 to 6 rank; anecdotally due to their Australian Graduate School of Entrepreneurship (AGSE) relaunch neither realizing former glory nor impact (despite nascent innovative developments to revive the AGSE). It also identifies notions in this article of the closeness of fit between entrepreneurship and innovation, whereby SUT is significantly active in the innovation and technology space (outside the ambit of this article). Another example of fluidity in rankings is UNSW Sydney (UNSW) which lost ground in the rankings, despite more than doubling the co-curricular offerings (Bliemel, 2017 ) through which they reached over 9,000 (or $\sim 15 \%$ of their 59,000 ) students (Zanich \& Olsen-Boyd, 2019). The University of Adelaide provided a sustainable rank ( 2 to 1 rank), evidenced by its Entrepreneurship and Commercialization Centre, recent entrepreneurship Chair appointment, significant engagement initiatives (such as inaugural Australian UIIN leadership) and significant senior leadership (an entrepreneurship Professor is a PVC).

It is noteworthy to mention the importance of academic research at Australian HEIs, both from impact and academic excellence perspectives. Although outside the ambit of this article, we acknowledge that 2 out of 3 of the top ranked HEIs in this research are Group of Eight (Go8) Universities (Adelaide and Queensland), traditionally high in research impact and excellence. Similarly, Queensland University of Technology (QUT) hosts the 
Australian Centre for Entrepreneurship (ACE), globally renowned as one of the global leaders in entrepreneurship research. From a regional perspective, Victoria has 4 HEIs in the top 10 ranking, somewhat resembling Boston (MA) as an entrepreneurship hub (MIT and Babson College). South Australia has 3 HEIs in the top 10, followed by 1 each for Queensland, New South Wales and the Australian Capital Territory.

\section{Figure 1: Entrepreneurship Education Ranking Fluidity at Australian Higher Education Institutions}

Insert Figure 1 about here; Figure is at the end of this paper.

Stage 2 Entrepreneurship Education Offerings (Qualitative)

Here we provided a nascent, emergent and open-ended inquiry approach to further inform stage 1 findings. Sixteen leading EE scholars/experts provided pattern identification from observations and presentations, together with narrative pieces from six of the top 10 HEIs in Table 1. This stage further informed a suggested theoretical underpinning applying substantive and symbolic approaches.

\section{Observations and Presentations}

This emergent enquiry perspective involved an integration of observations and presentations at the 2019 Entrepreneurship Education Forum; a forum hosted at the Sydney School of Entrepreneurship as a pre-event of the Australian Centre for Entrepreneurship Research (ACERE, 2019). Aligned to the emerging scholarship of EE identified in the literature review, these observations and presentations were centered on 4 themes: engaged learning, beyond entrepreneurship education, EE tools and micro credentialing. In the next section, we identify emergent enquiry perspectives under each theme:

Engaged learning: new perspectives on the student learning contract; entrepreneurial techniques through action-learning to teach internationalization; exploring a quadrant model approach for evolving business higher education in the entrepreneurial age and decision making theories and tools in entrepreneurship education (EE scholars include Balan, Restall, Mackay, Fiedler, Vidal, Mackenzie, Halvorson, Tsipidis, and Pokidko). This theme significantly aligns with the EEPs research of Maritz (2017) and scholarship of learning and teaching EE of Neck and Corbett (2018).

Beyond entrepreneurship education: Incorporating entrepreneurship education and skills outside of entrepreneurship courses; Innovation and new product and venture development in a higher education and sustainability context and adding value through practitioner engagement (EE scholars include Zaheer, Anisimova, Ferri and Gordon). This theme significantly aligns with the future trajectory of entrepreneurship (Kuratko \& Morris, 2018).

Entrepreneurship education tools: From virtual classroom to boardroom: engaging students with an entrepreneurial approach to coaching and developing a fully online asynchronous program; The use of QR codes in summative review of experiential EE and minimum viable planning cards (EE scholars include Marchand, Senyard, Brown, Phillips, Gilfedder and Bliemel). This theme significantly aligns to frameworks and support in the OECD/EU (2018) research.

Micro-credentialing: Redefining the honours degree to create a pan-university pathway to entrepreneurship: integrating modularized learning with blended and work integrated approaches; micro-credentialing of entrepreneurship education in a practice-based undergraduate engineering context, a cautionary note on microcredentialing and the influence of trust on entrepreneurial learning during a 
startup accelerator (EE scholars include Schweitzer, Marchand, Bliemel, Eager, Cook, Phelan, Glackin ,O'Connor and Dissanayake). This theme aligns with global EE imperatives from the QAA (2018) research.

These emergent enquiry perspectives provided both substantive and symbolic approaches to EE, where substantive approached 'lifted the tide' at the HEI and contributed to an integrated strategy towards being an entrepreneurial university. Symbolic approaches are more readily adopted and can contribute to being an entrepreneurial university, but can also occur in isolation from such an overall strategy.

From a substantive perspective, evidence was provided from empirical findings regarding validated outcomes of various EE imperatives. From a symbolic perspective, fourteen out of sixteen participants provided inference of a lack of appropriate financial and institutional resource for the optimal development of university-wide EE in HEIs. Furthermore, these same participants amplified emergent trends of HEIs participating in entrepreneurship ecosystems, despite a lack of strategic intentions to prioritise entrepreneurship by the HEI. This aspect is further addressed in stage 3 of the research findings in this paper.

An interesting finding raised at the ACERE (2019) forum was the aspect of staff mobility between HEIs, particularly when knowledgeable EE educators transferred previous EE skills at new institutions. New Institutions would then show both substantive and symbolic EE growth in initiatives and impact, usually a direct result of previous educator experience and skills. This transfer of mobility skills and knowledge aligns with EE impact and outcomes between HEIs, as evidenced in the literature (Maritz, 2017; Neck \& Corbett, 20128 and Kuratko \& Morris, 2018). An example in point is the departure of key entrepreneurship staff from Swinburne University over the past few years, and the subsequent growth in EE initiatives at the new HEIs these scholars joined. Practice based evidence of such knowledge transfer has been demonstrated at La Trobe and Flinders Universities.

\section{Entrepreneurship Narratives}

This emergent enquiry perspective involved narratives from the 6 leading HEIs identified in Table 1.

The University of Adelaide: The University of Adelaide adopts a holistic 3Dimensional approach to entrepreneurship. It fuses its academic Bachelor and Master entrepreneurship educational course-work programs with its non-academic new venture ThincLab incubation, eChallenge pre-acceleration, and Xelarite acceleration activities, and combines these two dimensions with a third "global reach" dimension. As such, entrepreneurship students at the University of Adelaide not only study entrepreneurship, they "do" entrepreneurship by applying what they have learned in the classroom to developing their own entrepreneurial ventures (or employer corporate ventures) while occupying space in the University's ThincLab Innovation Hubs. To develop international entrepreneurial perspectives and strategies, students can spend time in one or more of the University's overseas ThincLabs while enrolled in their studies developing export strategies for their ventures. (Professor Noel Lindsay, Professor of Entrepreneurship and Commercialisation, Pro Vice Chancellor Entrepreneurship and Dean of Business, Adelaide Business School).

University of Queensland: Over the last few years, UQ has developed a strategic approach to building entrepreneurship with a strong pathway between curricular and extra-curricular activities for students, alumni, staff, industry partners and other stakeholders. These activities, which include the Idea Hub pre-incubator, Start-up 
Academy from the business school, iLab accelerator with its Germinate program, and seed funding, support students and others through their own entrepreneurial journeys with expanded activities providing increased support from ideation through to application and scaling for impact. At the business school, an undergraduate and postgraduate major, Master of Entrepreneurship and Innovation, and other programs, provide hands-on opportunities for students to enhance their entrepreneurship mindset and skills. Entrepreneurs-in-residence and academic staff contribute to the entrepreneurship ecosystem through mentoring, and design and delivery of programs, including the national ON Prime program (Professor MartieLouise Verreynne, Professor of Innovation, The University of Queensland Business School).

University of Technology Sydney: Over the last few years, University of Technology Sydney (UTS) introduced a Master of Business Administration in Entrepreneurship (MBAe) and Bachelor of Entrepreneurship (Honours). It also created a new faculty, the Faculty of Transdisciplinary Innovation (FTDI), to break down silos and take a more holistic approach to research, teaching and engagement about innovation and entrepreneurship. Among other programs, FTDI offers a university-wide doubledegree Bachelor of Creative Intelligence and Innovation (BCII), including multiple entrepreneurship subjects and offers the Diploma in Innovation, half of which is entrepreneurship, available to all non-BCII undergraduates. In the Faculty of Engineering and IT, entrepreneurship subjects are now required for all students. On the extra-curricular side, an incubator and pre-accelerator was launched that won a AFR Higher Education award. The program was leveraged into UTS Startups, supporting over 130 startups by the end of 2018. A key component of the UTS Startups strategy is to connect to co-working spaces, incubators and accelerators that are off-campus, such as through partnerships with Fishburners and BlueChilli. (Dr Martin Bliemel, Director, Diploma in Innovation, University of Technology Sydney).

La Trobe University: Over the past few years, La Trobe University introduced Entrepreneurship Essentials, whereby every university degree requires embedding entrepreneurship content and outcomes. This resulted in significant subject development in multiple disciplines such as health sciences, engineering, social sciences and law. The La Trobe Business School introduced a Chair in Entrepreneurship, multiple Professors of Practice, development of a Masters of Entrepreneurship, a Business School wide compulsory undergraduate entrepreneurship subject and a suite of online entrepreneurship courses and subjects. The La Trobe Accelerator, an award-winning joint initiative between Deakin and Federation Universities and LaunchVic provides nascent entrepreneurs (including entrepreneurship coursework students) across Victoria the opportunity to enhance their entrepreneurial skills to launch successful startups (Professor Alex Maritz, Professor of Entrepreneurship, La Trobe Business School).

Flinders University: The New Venture Institute, focuses on three areas of I\&E education: Creating Startups, Acceleration and Capability building. The latter is a strategic spearhead for the university, aiming to teach all students one topic and 30\% doing more in 2022. This is done in a holistic, experiential, immersive I\&E program that speaks to a range of fields (not only business), improving the student experience and outcomes upon graduation. International collaboration (Tec Monterrey, Mondragon University, Temple University Philadelphia) and hands on experience has led to valuable learning, e.g. around cultures across schools, educating the Educators and Innovative (Online) Delivery methods. The pre-Accelerator Venture Dorm won a Top Challenger Asia Pacific award in 2017 (UBI), and NVI accelerates in an Industry4.0 Innovative Manufacturing Acceleration program (IMA), and a Social Enterprise acceleration series, Shift.ed (Bert Verhoeven, Head of Entrepreneurship Programs, The New Venture Institute, Flinders University). 
Swinburne University of Technology: Entrepreneurship, technology and innovation are at the heart of Swinburne University of Technology vibrant entrepreneurship ecosystem. In 2001, Swinburne established the first dedicated entrepreneurship school, the Australian Graduate School of Entrepreneurship (AGSE), and its flagship program the Master of Entrepreneurship and Innovation (MEI), which is delivered in collaboration with the International Institute of Entrepreneurship at Pitcher Partners. Led by the Faculty of Business and Law, the AGSE is connected to the wider university through our Innovation Hub, Digital Innovation Lab, Business Incubator Program and Entrepreneur-in-residence program. Within the Swinburne Entrepreneurship Ecosystem, we develop entrepreneurs who intend to start and grow their own business, and intrapreneurs, those interested in using the same skills and knowledge in a corporate environment. (Professor Milé Terziovski, Professor of Entrepreneurship and Innovation and Department Chair, Business Technology and Entrepreneurship).

Best practice initiatives identified in the above narratives primarily align to substantive theoretical underpinnings, with marginal symbolic inferences regarding brand image and participation in entrepreneurship ecosystems. We are mindful that many HEIs are currently expanding their entrepreneurial ecosystems and symbolic and/or substantive actions with entrepreneurship development. Examples include senior executive appointments, such as QUT; nascent departmental EE launches, such as Griffith University; and significant integration of start-up activities, such as the Sydney School of Entrepreneurship. Most of these initiatives are either nascent or in the development phase, hence predominantly outside of the current analyses of this paper.

\section{Stage 3 Entrepreneurship Education and HEI Entrepreneurship Strategic Intent (Leximancer Algorithm)}

Our final stage included analysis using Leximancer, applying statistical content analysis algorithms to measure the prevalence and cohesiveness of Australian HEIs strategic intent with respect to EE as articulated in their strategic plans. As a basis of comparison, we used the research of Nguyen and Maritz (2019) to provide foundations from global exemplar entrepreneurial universities, coupled with their framework for entrepreneurial university transformation. Pillars included entrepreneurship intent on the following factors: (1) strategic management, (2) entrepreneurial culture, (3) community connections and commercialization, (4) resource development and supporting mechanisms, and (5) teaching and research. Overall, Australian HEIs reveal a moderate level of determination to entrepreneurship transformation (average rating of 1.3), with only 6 HEIs revealing significant levels (rating of 3). Please refer to Table 1 for ratings by HEI.

The top ten HEIs all revealed ratings of significant or moderate determination, whereas the balance revealed much weaker determinations. These ratings, combined with the uneven distribution of EE programs across HEIs highlight the disparity of distribution of entrepreneurship from a strategic perspective, whereby moderate to significant transformation determination is only revealed by approximately forty-two percent of Australian HEIs. Substantive foundations may be across all levels, in that an HEI may express low levels of support for EE in their strategic intent and simultaneously offer low levels of EE programs; same for high-high pairing. Symbolic action occurs when there is incongruence between the strategic intent and offerings, as visualized in the lower right of Figure 2. Some abbreviated HEI labels were removed for visual clarity because the labels overlapped. Where the threshold between substantive and symbolic foundations is remains to be determined, and may be relative within the Australian HEI sector, or relative to international HEIs. We note that strategic intent documents and EE programs change over time, and that further research is required to study their interdependence.

Figure 2: Substantive and Symbolic EE at Australian HEIs 
While it remains debatable which proportion of HEIs have symbolic foundations, the results show that only twenty-eight percent of HEIs in Australia espouse high levels of support for EE when measured on the basis of strategic intent on entrepreneurship transformation. This echoes the observations at the ACERE forum that the majority of presenting scholars perceived a lack of appropriate financial and institutional resources for university-wide EE support.

\section{Conclusion}

In this article, embedding entrepreneurship in education makes multiple contributions to the scholarship and study of EE and the transformation of entrepreneurship in HEIs more broadly. First is the neoteric and updated status of EE across all 40 Australian HEIs, a replication and extension of a similar study 5 years ago. This empirical analysis is set against a backdrop of prior reviews of the state of EE at HEIs in the UK, the Netherlands or the USA, that document recent trends towards holistic, robust and integrative approaches to embedding EE in HEIs. In comparison to these international benchmarks, this study identifies opportunity areas to enhance EE offerings and initiatives in Australian HEIs, further enhancing impact within start-up and entrepreneurship ecosystems. This contrast is complemented or even exacerbated by the contrast between EE programs at HEIs versus the rapidly emerging private sector EE programs. Recognition of the gap between where Australian HEI-based EE programs are versus where they could be creates the need for a more nuanced understanding of the contextualization of global best practice and exemplar EE programs and initiatives, particularly methodological issues and pedagogical methods that underpin them.

Second, focusing only on the updated status of EE in Australia, this study reveals a troubling decline in EE programs across the aggregated HEI sector, especially at the level of subjects. Meanwhile, the same data reveals how volatile or fluid the rankings of HEIs are across all ranks. The volatility can be interpreted several ways. Either emerging HEIs are pushing out otherwise stable incumbents, or incumbents are simply lowering their EE offerings. And, for almost all HEIs, there is little guarantee that EE support for one episode may be the same in the next episode. The latter point of uncertain support for EE is poignant to faculty members who may switch HEIs to contribute to boosting EE programs at their new home. The above analysis includes evidence of staff mobility and transferability of skills between HEIs, whereby staff moving from one institution to another results in a significant increase in EE initiatives at the new institution. Altogether, this has implications on recruiting and retention policies as well as a need for consistent support for EE across all administrative ranks if an HEI is to build and sustain (global) leadership in EE.

Finally, and building on the above, this study analyses the importance of HEIs strategic intent and delivery of quality EE to demonstrate symbolic and substantive theoretical underpinnings to entrepreneurial university transformation. Overall, this provides a framework and critical grounding for researchers, practitioners and HEIs wishing to enhance EE within ever-expanding entrepreneurship ecosystems. From a substantive perspective, this article highlights the sparse and inconsistent distribution of EE programs and initiatives at Australian HEIs, particularly against the backdrop of rapidly expanding start-up and entrepreneurship ecosystems. Neoteric reviews highlight benchmark and prominent EE programs and initiatives that may be impactful and measurable across global boundaries, particularly when measuring country/contextual specific attributes. Observations and presentations identified significant substantive EE application, with symbolic approaches centered on lack of strategic intent and support of entrepreneurship within HEIs. The narratives provided by 6 of the top HEIs provided specific best practice EE initiatives and provided an additional layer of validity to the EE rankings and Leximancer analysis. We also examined the interface between HEI strategic intentions and delivery of EE, thereby identifying the possibility of symbolic nature of EE 
across the majority of Australian HEIs. Identifying attributes to progressive and strategic entrepreneurship transformation and enhancing substantive foundations as evidenced by the top 10 HEIs in Table 1, provide a framework for successfully embedding EE within HEIs. Not only do these HEIs embed EE into their offerings, but also enhance local entrepreneurship ecosystems.

Despite the symbolic nature, the lag on global and private-sector competitiveness, and the relatively flat plateau of HEI entrepreneurship programs, there is, however, optimism for growth of the discipline. This is evidenced by a significant increase in Chairs or heads of the entrepreneurship discipline, an increase in entrepreneurs in residence, University wide incubators and accelerators, and proactive growth of new players in the space (such as Flinders, Canberra and La Trobe). Many HEIs are also actively engaging entrepreneurship from a strategic perspective, evidenced by senior executive leadership appointments in this domain. The University of Adelaide, University of Queensland, QUT and UTS are examples of such initiatives.

Our new insights provide a measure of the status of EE programs and initiatives at a point in time, and primarily subject to content analysis from documents and material resources on HEI websites. As such, a limitation of the data is subject to availability and accuracy of such documents and material resources. This limitation was partially mitigated by sharing preliminary outcomes with prominent EE scholars at the ACERE forum, together with qualitative data collection and analysis. As the quantitative analysis was primarily descriptive, an opportunity for further research includes empirical studies of the outcomes and impact of EE in HEIs. Furthermore, we suggest similar global studies, whereby the three main patterns/research gaps identified in this article may be replicated and extended globally. From a practice perspective, we encourage prominent HEIs to share their EE initiatives with other Australian and global HEIs. Despite identified shortcomings regarding EE programs and initiatives in this research, we are of the opinion that HEIs in Australia are experiencing a moderate EE boom, albeit marginally down on global EE transformation initiatives.

\section{REFERENCES}

Alexander, J. 2018 Universities are jumping into Australia's startup boom.

https://www.linkedin.com/pulse/universities-jumping-australias-startup-boom-jamesalexander

Alberti, F., Sciascia, S. \& Poli, A. Entrepreneurship education: notes on an ongoing debate. Proceedings of the 14th Annual IntEnt Conference, University of Napoli Federico II, Italy, 2004.

Australian Centre for Entrepreneurship Research Exchange (ACERE, 2019). Australian Centre for Entrepreneurship (ACE) Research Exchange Conference, 2019 Sydney, Australia. Research Exchange and Entrepreneurship Education Forum.

Belitski, M. \& Heron, K. 2017. Expanding entrepreneurship education ecosystems. Journal of Management Development, 36, 163-177.

Bliemel, M. 2017. UNSW Startup Road Map. In (Eds. Furber, B. \& Griffith, S.) Michael Crouch Innovation Centre: An Emergent Force. UNSW Sydney. http://nla.gov.au/nla.obj$\underline{451855707}$

Bliemel, M. 2019. Should all students get a taste for entrepreneurship? https://www.linkedin.com/pulse/should-all-students-get-taste-entrepreneurshipmartin-bliemel/ 
Bliemel, M., Flores, R., De Klerk, S. \& Miles, M. P. 2019. Accelerators as start-up infrastructure for entrepreneurial clusters. Entrepreneurship \& Regional Development, 31, 133-149.

Edmondson, A. C. \& McManus, S. E. 2007. Methodological fit in management field research. Academy of management review, 32, 1246-1264.

Fayolle, A. \& Gailly, B. 2008. From Craft to Science: Teaching Models and Learning Processes in Entrepreneurship Education. Journal of European Industrial Training, 32, 569-593.

Jones, C., Matlay, H., Penaluna, K. \& Penaluna, A. 2014. Claiming the future of enterprise education. Education \& Training, 56, 764-775.

Keegan, S. 2009. "Emergent inquiry" A practitioner's reflections on the development of qualitative research. Qualitative Market Research: An International Journal, 12, 234-248.

Kuratko, D. F. \& Morris, M. H. 2018. Examining the future trajectory of entrepreneurship. Journal of Small Business Management, 56, 11-23.

Liguori, E., Bendickson, J., Solomon, S. \& McDowell, W. C. 2019. Development of a multidimensional measure for assessing entrepreneurial ecosystems. Entrepreneurship \& Regional Development, 31, 7-21.

Maritz, A. 2017. Illuminating the black box of entrepreneurship education programmes: part 2. Education+ Training, 59, 471-482.

Maritz, A. \& Brown, C. R. 2013. Illuminating the Black Box of Entrepreneurship Education Programs. Education \& Training, 55, 234-252.

Maritz, A. \& Donovan, J. 2015. Entrepreneurship and innovation: Setting an agenda for greater discipline contextualisation. Education+ Training, 57, 74-87.

Maritz, A., Jones, C. \& Shwetzer, C. 2015. The status of entrepreneurship education in Australian universities. Education+ Training, 57, 1020-1035.

Mason, C. (2019). Keynote address, Entrepreneurship Ecosystems. Australian Centre for Entrepreneurship (ACE) Research Exchange Conference, 2019 Sydney, Australia.

Miles, M. P., de Vries, H., Harrison, G., Bliemel, M., de Klerk, S. \& Kasouf, C. J. 2017. Accelerators as Authentic Training Experiences for Nascent Entrepreneurs. Education \& Training, 59, 811-8), p.811-824.

Morris, M. H. \& Kuratko, D. F. 2014. Building university 21st century entrepreneurship programs that empower and transform. Advances in the Study of Entrepreneurship, Innovation, and Economic Growth, 24, 1-24.

Morris, M. H., Kuratko, D. F. \& Cornwall, J. R. 2013. Entrepreneurship programs and the modern university, Edward Elgar Publishing.

Nabi, G., Liñán, F., Fayolle, A., Krueger, N. \& Walmsley, A. 2017. The impact of entrepreneurship education in higher education: A systematic review and research agenda. Academy of Management Learning \& Education, 16, 277-299.

Neck, H. M. \& Corbett, A. C. 2018. The scholarship of teaching and learning entrepreneurship. Entrepreneurship Education and Pedagogy, 1, 8-41. 
Nguyen, Q. A. \& Maritz, A. Entrepreneurship as a strategic imperative in Australian universities. Australian Centre for Entrepreneurship (ACE) Research Exchange Conference, 2019 Sydney, Australia.

O'Connor, A. 2013. A conceptual framework for entrepreneurship education policy: Meeting government and economic purposes. Journal of Business Venturing, 28, 546563.

OECD/EU 2018. Supporting entrepreneurship and innovation in higher education in the Netherlands. OECD Skills Studies, OECD Publishing.

Pfeffer, J. 1981. Management as symbolic action: the creation and maintenance of organizational paradigm. Research in organizational behavior, 3, 1-52.

QAA 2018. Enterprise and entrepreneurship education: Guidance for UK higher education providers.

Renando, C. 2018. A map of the Australian Innovation Ecosystem 2.0. Available: https://www.linkedin.com/pulse/map-australian-innovation-ecosystem-20-chadrenando/.

Scandlon, C. \& McCormack, S. 2018. Challenges and Opportunities: A closer look at entrepreneurship education in Australian universities UIIN BLOG. Available: https://blog.uiin.org/2018/12/challenges-opportunities-closer-look-entrepreneurshipeducation-australian-universities/ [Accessed 15 January 2019].

Spigel, B. 2017. The relational organization of entrepreneurial ecosystems. Entrepreneurship Theory and Practice, 41, 49-72.

Universities Australia. 2017. Universities and the startup economy. https://www.universitiesaustralia.edu.au/australias-universities/Universities-and-thestartup-economy

World Economic Forum. 2018. The Future of Jobs Report 2018. https://www.weforum.org/reports/the-future-of-jobs-report-2018

Zanich, J. \& Olsen-Boyd, A. 2019. UNSW Founders Program: Effective Entrepreneurship at Scale in a University. Presented at the University-Industry Engagement Conference, Sydney, NSW 


\section{Table 1: Entrepreneurship Education Initiatives at Australian HEIs}

\begin{tabular}{|c|c|c|c|c|c|c|c|c|c|c|c|c|c|c|c|}
\hline 2019 & 2015 & HEI & $\begin{array}{c}\text { Full } \\
\text { program } \\
\text { (6) }\end{array}$ & $\begin{array}{c}\text { Program } \\
\text { with MAJOR } \\
\text { specialisation } \\
\text { (4) } \\
\end{array}$ & $\begin{array}{c}\text { Program } \\
\text { with MINOR } \\
\text { specialisation } \\
\text { (2) } \\
\end{array}$ & $\begin{array}{c}\text { Subject } \\
\text { about } \\
\text { or core } \\
(2) \\
\end{array}$ & $\begin{array}{l}\text { Subject } \\
\text { related } \\
\text { (1) }\end{array}$ & $\begin{array}{c}\text { Online } \\
\text { (additional } \\
\text { or solely) } \\
(2 / 1) \\
\end{array}$ & $\begin{array}{l}\text { Chair } \\
\text { (3) }\end{array}$ & $\begin{array}{l}\text { Entrepreneur } \\
\text { in residence } \\
\text { (2) }\end{array}$ & $\begin{array}{l}\begin{array}{c}\text { Professor } \\
\text { of } \\
\text { Practice } \\
\text { (2) }\end{array} \\
\end{array}$ & $\begin{array}{c}\text { Incubator / } \\
\text { Accelerator } \\
\text { program } \\
\text { (2) } \\
\end{array}$ & $\begin{array}{c}\text { Ecosystem } \\
\text { (2) }\end{array}$ & $\begin{array}{c}\text { Strategic } \\
\text { Intent } \\
\text { Leximancer } \\
(0-3) \\
\end{array}$ & Total \\
\hline 1 & 2 & Adelaide & 12 & 0 & 2 & 66 & 4 & 8 & 3 & 2 & 0 & 2 & 2 & 3 & 104 \\
\hline 2 & 9 & UTS & 12 & 4 & 4 & 44 & 24 & 0 & 0 & 0 & 0 & 2 & 2 & 2 & 95 \\
\hline 3 & 4 & QLD & 6 & 8 & 2 & 46 & 5 & 5 & 3 & 2 & 2 & 2 & 2 & 2 & 85 \\
\hline 4 & 21 & La Trobe & 0 & 12 & 6 & 22 & 10 & 14 & 3 & 2 & 2 & 2 & 2 & 3 & 78 \\
\hline 5 & 18 & Flinders & 6 & 4 & 0 & 40 & 8 & 1 & 0 & 2 & 0 & 2 & 2 & 3 & 68 \\
\hline 6 & 1 & Swinburne & 6 & 4 & 0 & 34 & 2 & 8 & 3 & 2 & 0 & 2 & 2 & 2 & 65 \\
\hline 7 & 5 & Melbourne & 6 & 0 & 0 & 36 & 6 & 0 & 3 & 2 & 0 & 2 & 2 & 3 & 60 \\
\hline 8 & 7 & RMIT & 0 & 8 & 2 & 33 & 4 & 2 & 3 & 0 & 0 & 2 & 2 & 2 & 58 \\
\hline 9 & 19 & Canberra & 0 & 8 & 0 & 14 & 2 & 23 & 3 & 2 & 0 & 2 & 1 & 3 & 58 \\
\hline 10 & 8 & Unisa & 0 & 4 & 2 & 24 & 2 & 13 & 0 & 2 & 0 & 2 & 1 & 2 & 52 \\
\hline 11 & 22 & QUT & 0 & 0 & 0 & 4 & 28 & 1 & 3 & 2 & 0 & 2 & 2 & 3 & 45 \\
\hline 12 & 12 & $\begin{array}{l}\text { Sunshine } \\
\text { Coast }\end{array}$ & 0 & 0 & 4 & 3 & 24 & 1 & 0 & 0 & 0 & 2 & 2 & 1 & 37 \\
\hline 13 & 11 & Tasmania & 6 & 0 & 0 & 26 & 0 & 0 & 0 & 0 & 0 & 2 & 1 & 2 & 37 \\
\hline 14 & 13 & Maqauarie & 0 & 8 & 2 & 20 & 0 & 0 & 0 & 0 & 0 & 2 & 2 & 2 & 36 \\
\hline 15 & 14 & Newcastle & 0 & 4 & 2 & 14 & 3 & 6 & 0 & 0 & 0 & 2 & 2 & 1 & 34 \\
\hline 16 & 17 & Bond & 0 & 0 & 0 & 26 & 1 & 2 & 0 & 0 & 0 & 2 & 1 & 2 & 34 \\
\hline 17 & 34 & Deakin & 0 & 4 & 2 & 13 & 2 & 4 & 0 & 0 & 0 & 2 & 1 & 1 & 29 \\
\hline 18 & $n / a$ & Torrens & 0 & 4 & 0 & 15 & 0 & 8 & 0 & 0 & 0 & 0 & 0 & 0 & 27 \\
\hline 19 & 33 & Murdoch & 0 & 4 & 0 & 14 & 4 & 0 & 0 & 0 & 0 & 2 & 2 & 1 & 27 \\
\hline 20 & 28 & Griffith & 0 & 4 & 0 & 11 & 0 & 5 & 3 & 0 & 0 & 0 & 2 & 2 & 27 \\
\hline 21 & 3 & Sydney & 0 & 0 & 0 & 18 & 1 & 0 & 3 & 0 & 0 & 0 & 0 & 2 & 24 \\
\hline 22 & 23 & ANU & 0 & 4 & 2 & 12 & 5 & 0 & 0 & 0 & 0 & 0 & 0 & 1 & 24 \\
\hline 23 & 6 & UNSW & 0 & 4 & 0 & 10 & 1 & 0 & 0 & 2 & 0 & 2 & 2 & 2 & 23 \\
\hline 24 & 10 & UWA & 0 & 0 & 2 & 10 & 1 & 0 & 0 & 2 & 0 & 2 & 2 & 1 & 20 \\
\hline 25 & 20 & Woolongong & 0 & 0 & 2 & 8 & 3 & 0 & 0 & 2 & 0 & 2 & 2 & 1 & 20 \\
\hline 26 & 15 & WSydney & 0 & 0 & 0 & 16 & 0 & 0 & 0 & 0 & 0 & 2 & 0 & 1 & 19 \\
\hline 27 & 37 & CQU & 0 & 0 & 2 & 10 & 2 & 0 & 0 & 0 & 0 & 0 & 0 & 0 & 14 \\
\hline 28 & 27 & Curtin & 0 & 0 & 2 & 8 & 0 & 0 & 0 & 2 & 0 & 2 & 0 & 0 & 14 \\
\hline 29 & 16 & Federation & 0 & 0 & 2 & 10 & 1 & 0 & 0 & 0 & 0 & 0 & 0 & 1 & 14 \\
\hline 30 & 26 & Victoria & 0 & 0 & 0 & 6 & 2 & 0 & 3 & 2 & 0 & 0 & 0 & 1 & 14 \\
\hline 31 & 32 & $\begin{array}{l}\text { Charles } \\
\text { Sturt }\end{array}$ & 0 & 0 & 1 & 4 & 1 & 0 & 3 & 0 & 0 & 2 & 1 & 1 & 13 \\
\hline 32 & 31 & Monash & 0 & 0 & 0 & 4 & 1 & 0 & 3 & 0 & 0 & 2 & 1 & 1 & 12 \\
\hline 33 & 36 & $\begin{array}{l}\text { Charles } \\
\text { Darwin }\end{array}$ & 0 & 0 & 0 & 0 & 1 & 1 & 0 & 2 & 0 & 2 & 1 & 0 & 7 \\
\hline 34 & 25 & $\begin{array}{l}\text { Southern } \\
\text { Cross }\end{array}$ & 0 & 0 & 0 & 4 & 0 & 1 & 0 & 0 & 0 & 2 & 0 & 0 & 7 \\
\hline 35 & 29 & James Cook & 0 & 0 & 0 & 4 & 1 & 2 & 0 & 0 & 0 & 0 & 0 & 0 & 7 \\
\hline 36 & 24 & Edith Cowan & 0 & 0 & 1 & 4 & 0 & 0 & 0 & 0 & 0 & 0 & 0 & 0 & 5 \\
\hline 37 & 38 & UNE & 0 & 0 & 2 & 2 & 0 & 0 & 0 & 0 & 0 & 0 & 0 & 0 & 4 \\
\hline 38 & 30 & USQ & 0 & 0 & 0 & 2 & 0 & 0 & 0 & 0 & 0 & 0 & 0 & 0 & 2 \\
\hline 39 & 35 & ACU & 0 & 0 & 0 & 0 & 2 & 0 & 0 & 0 & 0 & 0 & 0 & 0 & 2 \\
\hline 40 & 39 & Notre Dame & 0 & 0 & 0 & 2 & 0 & 0 & 0 & 0 & 0 & 0 & 0 & 0 & 2 \\
\hline & \multicolumn{2}{|c|}{ TOTAL POINTS } & 36 & 100 & 44 & 639 & 151 & 105 & 39 & 30 & 4 & 54 & 42 & 52 & 1298 \\
\hline & \multicolumn{2}{|c|}{ Total Count } & 9 & 22 & 22 & 319.5 & 143 & 189 & 13 & 15 & 2 & 27 & 21 & 1.3 AVE & $32.4 \mathrm{AVE}$ \\
\hline
\end{tabular}


Figure 1: Entrepreneurship Education Ranking Fluidity at Australian HEIs

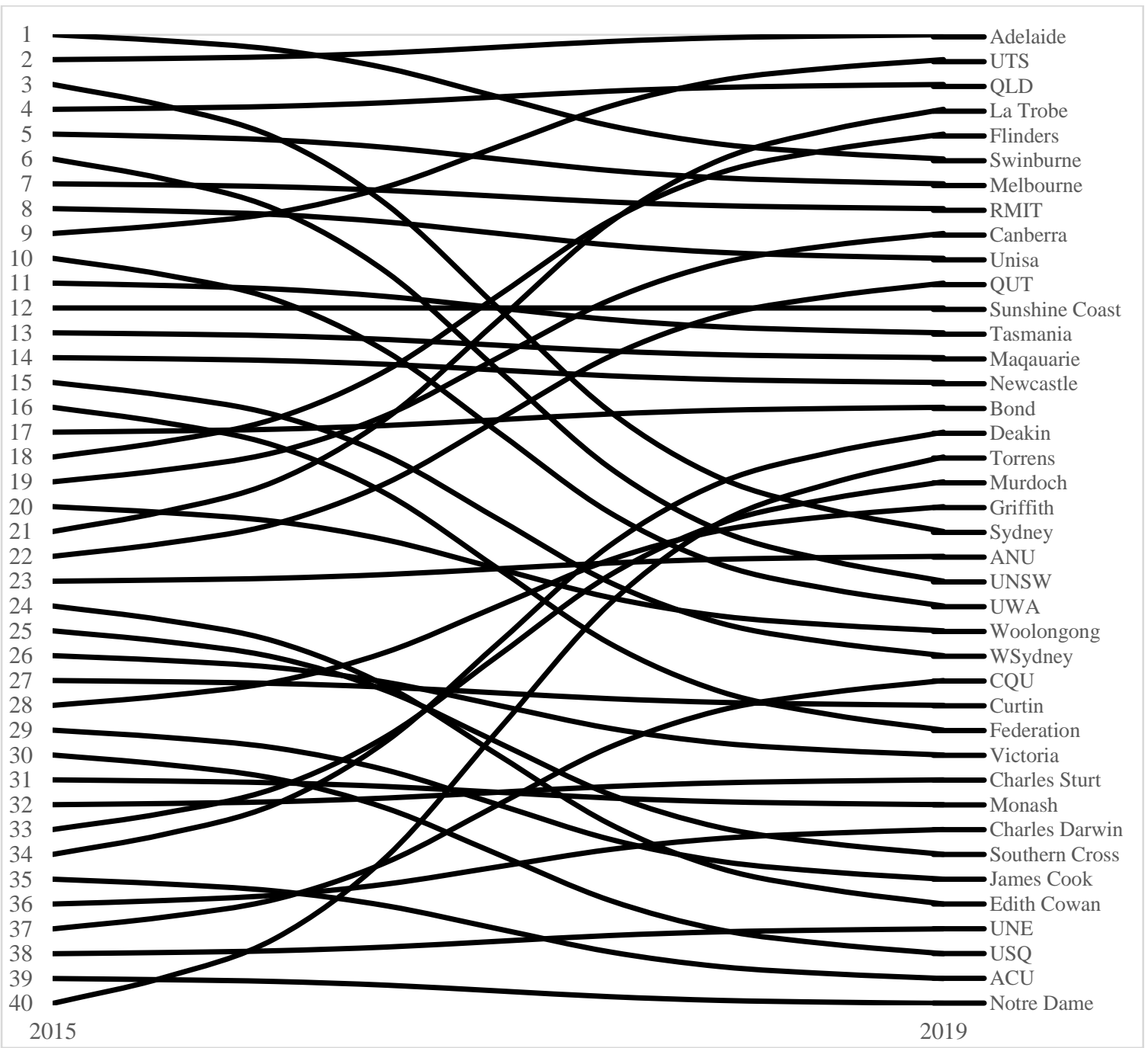


Figure 2: Substantive and Symbolic EE at Australian HEIs

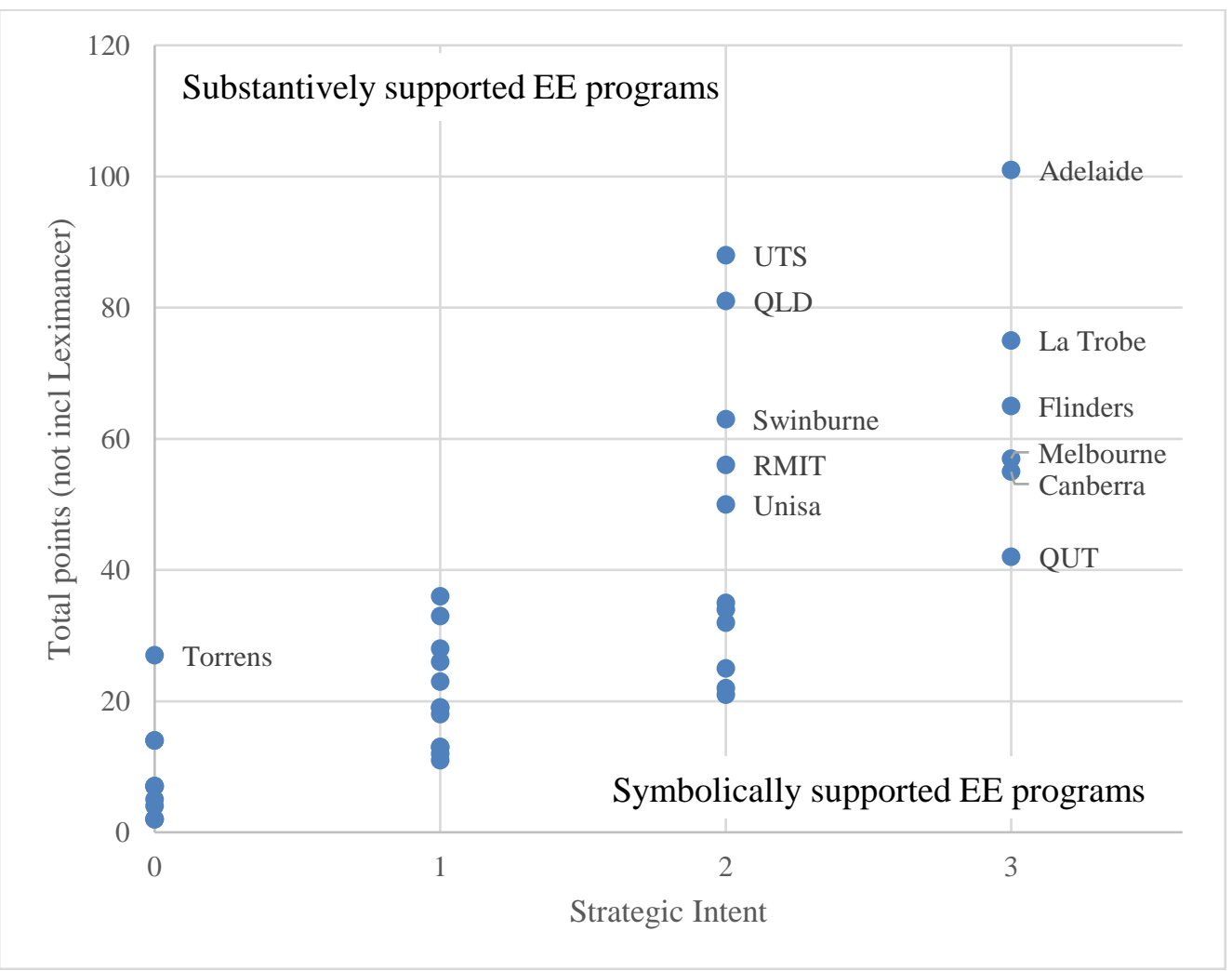

